\title{
Production of Hollow Spheres of Eutectic Tin-Lead Solder through a Coaxial Nozzle*
}

\author{
Truong V. VU**, Hideyuki TAKAKURA**, John C. WELLS** \\ and Takashi MINEMOTO*** \\ ${ }^{* *}$ Graduate School of Science and Engineering, Ritsumeikan University, \\ 1-1-1 Nojihigashi, Kusatsu, Shiga 525-8577, Japan \\ E-mail:gr042084@ed.ritsumei.ac.jp \\ ***Ritsumeikan Global Innovation Research Organization, Ritsumeikan University, \\ 1-1-1 Nojihigashi, Kusatsu, Shiga 525-8577, Japan
}

\begin{abstract}
Hollow eutectic tin-lead solder spheres with diameters from 3.5 to $4.5 \mathrm{~mm}$ have been produced directly from the melt. Raw solder placed in a crucible was melted at a temperature of typically about $50{ }^{\circ} \mathrm{C}$ above its melting point. The molten solder was then extruded vertically downward into air at room temperature through the outer nozzle of a coaxial nozzle mounted at the crucible bottom. Capillary instability of the extruded hollow molten solder jet led to the formation of hollow solder spheres. This formation was assisted by a transverse nozzle placed close to the coaxial nozzle, which directed an inert gas past the hollow jet at position where sphere detached. The spheres were then quickly cooled and solidified by water mist prior to collection in a container filled with water. Most of these spheres were completely hermetic and had a relatively smooth surface. Hollow water spheres were also formed as a test of production of hollow solder spheres through the nozzle.
\end{abstract}

Key words: Eutectic Tin-Lead Solder, Hollow Solder Sphere, Coaxial Nozzle, Transverse Nozzle

\section{Introduction}

Hollow metal spheres with diameters typically in the range of 1.5 to $10 \mathrm{~mm}$ have found application in a new group of cellular metals, metallic hollow sphere structures, which have excellent properties for noise absorption, impact absorption, heat dissipation and light weight construction ${ }^{(1)}$. The spheres are typically expected to have a smooth and hermetic surface, round shape and concentric inner and outer spherical surfaces. In other application, it may be necessary to produce spheres of high precision and strength, such as rapidly reacting metal ball valves and bearings ${ }^{(2)}$. For application to electrical and electronic devices, the purity of hollow sphere materials is important, as impurities might degrade device performance. Accordingly, a simple method capable of producing hollow metal spheres with no impurities is desirable. The objective of the present study is to produce hollow eutectic tin-lead solder spheres by a simple process and apparatus. Hollow spheres of solder might be applied to ball grid arrays (BGAs) although they would have to be smaller than those reported here. It appears that the production of hollow eutectic tin-lead solder spheres has not been reported in the literature.

*Received 29 July, 2010 (No. 10-0313) [DOI: 10.1299/jmmp.4.1530]

Copyright $@ 2010$ by JSME 
There have been several methods developed to form of hollow metal spheres. Waag et al. ${ }^{(3)}$ coated a layer of metal powder and binders on to polymer cores. When the coating was heated to a temperature from 400 to $500{ }^{\circ} \mathrm{C}$, the polymer particles and part of the binder were pyrolized. The resulting hollow metal spheres were sintered at just below the melting temperature of the sphere materials. This method can produce hollow spheres of such materials as metals, alloys and ceramics. However, it cannot produce hollow spheres of low melting temperature metals such as aluminum, zinc or tin ${ }^{(2)}$. Futhermore, hollow metal spheres produced in this way unavoidably include contaminants such as residues of carbon and other elements ${ }^{(3)}$.

In another method ${ }^{(4)}$, Torobin used a coaxial nozzle to form hollow metal spheres that contained a gas or a vacuum within the spheres. This method is capable of forming hollow spheres of pure metals and alloys that have low to high melting temperatures, provided that the materials have a sufficiently high viscosity and a suitable surface tension. Spheres can be produced in various sizes and wall thicknesses.

Using the same technique as described in Ref. (4), but instead of using a transverse nozzle, Nadler et al. ${ }^{(5)}$ used a co-flowing surrouding gas of argon to assist in the formation of aluminum hollow spheres. The spheres produced had a hermetic, relatively constant wall thickness and diameter. Among the materials that they investigated, aluminum- $2 \%$ calcium showed the most promise because of the presence of oxide particles working as hollow sphere formation stabilizers. However, the introduction of a co-flowing surrounding gas increases the falling distance for complete solidification of spheres. Additionally, it might increase the chance of satellite sphere formation resulting in non-uniformity and sphere collision.

In this study, we produced hollow eutectic tin-lead solder (Sn63Pb37) spheres by a method based upon that developed by Torobin ${ }^{(4)}$. The most important part of the method is the coaxial nozzle that forms the hollow molten metal jet. An inner nozzle discharges an inert gas, such as argon, while the surrounding annular gap discharges molten metal. The hollow jet breaks into hollow drops due to the effect of capillary instability. The formation and detachment of hollow spheres is promoted by using a transverse nozzle that directs a gas past the hollow jet. The spheres are then rapidly cooled and solidified by a quench liquid sprayed from a second nozzle below. The transverse nozzle in our study was placed slightly below the coaxial nozzle whereas, in the work described by Torobin ${ }^{(4)}$, the jet was directed obliquely from above. With our apparatus, the transverse jet directly acted in the region of sphere breakup. The selection of the method is due to (1) the low melting temperature of eutectic tin-lead solder $\left(183{ }^{\circ} \mathrm{C}\right)$, (2) the simplicity of the process and apparatus and (3) the goal of hollow spheres with no contaminants such as residues of carbon. We used eutectic tin-lead solder with no additives such as viscosity stabilizers and surface active agents. Therefore, there were no contaminants from these additives in the hollow sphere shells.

\section{Method and experimental materials}

2.1 Apparatus and method description

The apparatus for producing hollow eutectic tin-lead solder spheres consists of a heating system, a gas system, a pressurized crucible and a coaxial nozzle. The

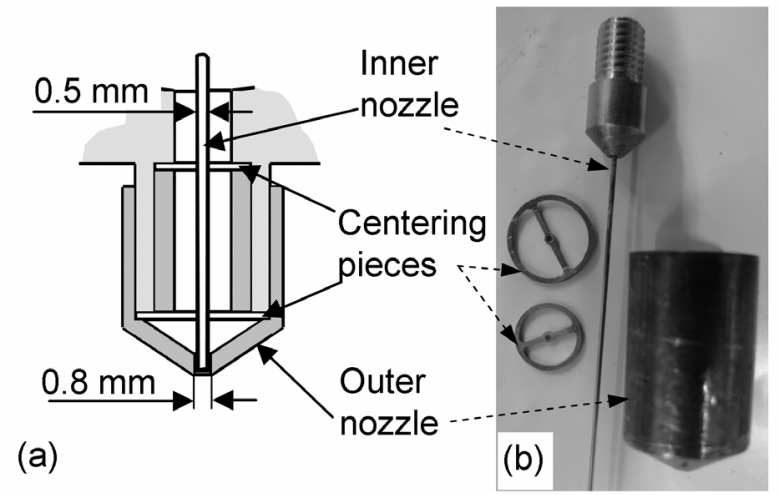

Fig. 1 (a) Cross-section of coaxial nozzle and (b) disassembled coaxial nozzle and centering pieces used in the study. 


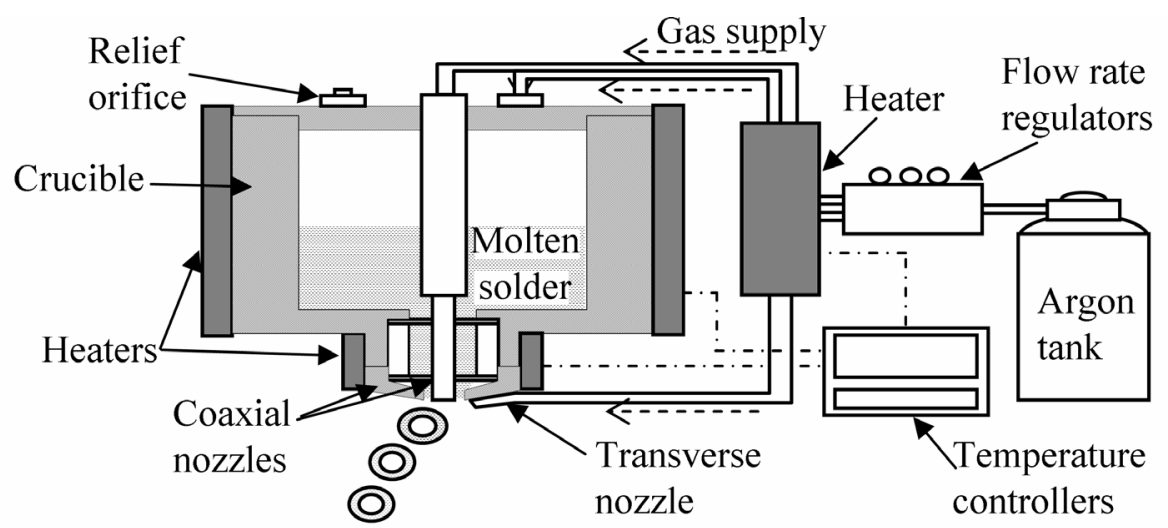

Fig. 2 Schematic of experimental apparatus for production of hollow eutectic tin-lead solder spheres.

crucible and coaxial nozzle are made of stainless steel. The gas system controls the flow rates of the outer jet of molten solder and of an inner jet of argon gas that emits from a lower part of the inner nozzle of $0.5 \mathrm{~mm}$ in outer diameter and $0.3 \mathrm{~mm}$ in inner diameter. This lower part is connected to an upper part of an outer diameter of $6 \mathrm{~mm}$ and an inner diameter of $4 \mathrm{~mm}$ that is fixed to the center of the crucible lid. The centering of the inner nozzle is accomplished by two centering pieces inserted in the outer nozzle. The outer nozzle has an inner diameter of $0.8 \mathrm{~mm}$. Figure 1 shows the main components of the coaxial nozzle and centering pieces utilized in our study.

The experimental apparatus setup for the production of eutectic tin-lead solder spheres is illustrated in Fig. 2. The heating system consisting of heaters and temperature controllers is used to melt eutectic tin-lead solder and heat the gas. Heaters include a pair of $400 \mathrm{~W}$ band heaters (model V1-140; Nippon Heater Co., Ltd., Japan) clamped around the crucible, a coil heater (model UWRPF2.2x4.2; Nippon Heater Co., Ltd., Japan) clamped around the outer nozzle of the coaxial nozzle and a micro heater (model MC2-102; Nippon Heater Co., Ltd., Japan) rolled around the gas conduits. In order to control the operating temperature of the heating system, two temperature controllers are used with K-type thermocouples. One of the temperature controllers (model MTCD; MISUMI Corp., Japan) is used to control the temperature of the crucible and coaxial nozzle. The other (model TR-KN; AS ONE Corp., Japan) is used to control gas temperature.

A transverse nozzle directing the argon gas at a suitable flow rate past the hollow molten solder jet is used to assist in formation and detachment of the hollow solder spheres. Its inner and outer diameters are respectively $3 \mathrm{~mm}$ and $6 \mathrm{~mm}$. A water sprayer used to quickly cool and solidify the hollow spheres is disposed at about 0.3 to $0.5 \mathrm{~m}$ below the coaxial nozzle. The spheres are collected after their flight by a container located at $2.5 \mathrm{~m}$ below the crucible. The container is filled with water that prevents a newly impinged semi-solid sphere from damaging the solidified spheres ${ }^{(5)}$ and works as a buffer medium. The water sprayer and collection container are not shown in Fig. 2. Observation of the sphere formation is accomplished by a high speed camera FASTCAM 1024 PCI (Photron, Japan) run at 2000 to 6000 frames per second (f.p.s).

Although the objective of the present study is the production of hollow eutectic tin-lead solder spheres, we first tested the performance of the

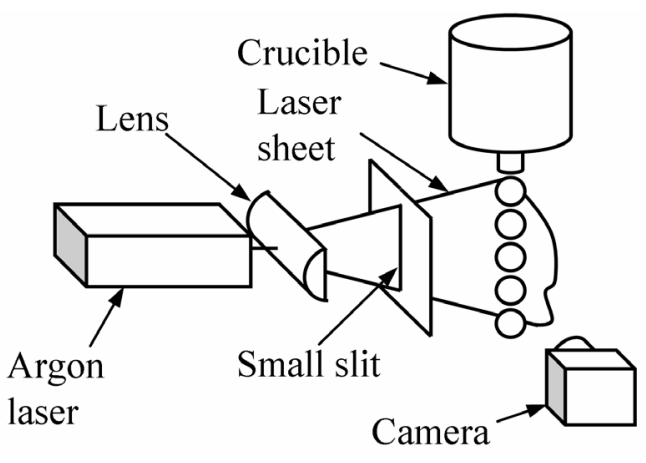

Fig. 3 Schematic of apparatus for the hollow water sphere formation. 


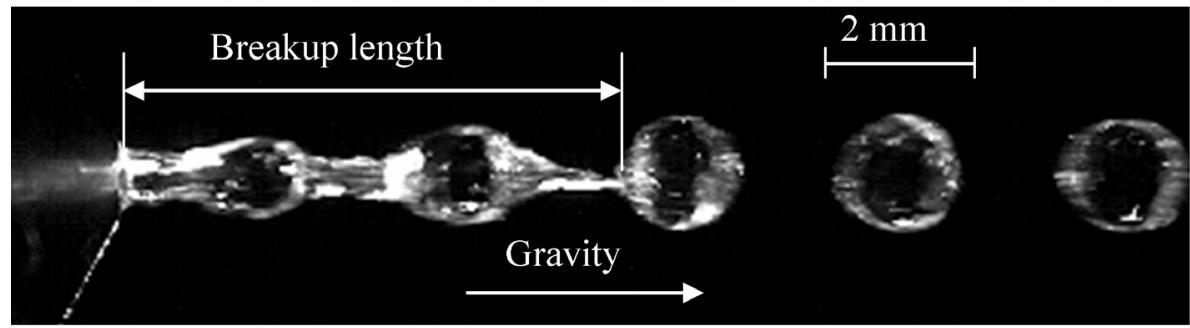

Fig. 4 Formation of hollow water spheres (case 33-67). Illumination is by 1-mm thick laser sheet as depicted in Fig. 3.

apparatus using water. The apparatus setup for the test is depicted in Fig. 3. In order to clearly observe the formation as well as the hollowness of water spheres, we seeded water with hollow glass sphere with a diameter on the order of $10 \mu \mathrm{m}$. The glass particle content in water was about $0.7 \mathrm{~g} / 1$. When these particles move within a laser sheet they scatter laser light that is imaged, as shown in Fig. 4, by the camera. The laser sheet has a thickness of about 1.0 to $1.5 \mathrm{~mm}$. The laser with wavelengths in the range 333 to $529 \mathrm{~nm}$ is an argon ion laser. A cylindrical lens expands the laser beam into a plane that is narrowed by a slit of less than $1 \mathrm{~mm}$ in width. The slit is placed close to the region of sphere formation (about $10 \mathrm{~cm}$ away from the center line of sphere chain). The sheet of laser light cuts vertically hollow spheres of seeded water at their center. The camera views perpendicular to the laser sheet. In the test, we did not use the heating system, transverse nozzle, nor water sprayer.

To produce hollow spheres of solder we followed the following steps: (1) Heat up the crucible and coaxial nozzle to a temperature of about $50{ }^{0} \mathrm{C}$ above the melting temperature of solder and maintain that temperature during the process. (2) Heat up gas to a temperature of about $300{ }^{0} \mathrm{C}$. (3) Once the solder in the crucible is completely molten, direct gas to the crucible to pressurize it and blow the molten solder out of annular space, simultaneously direct gas to the inner nozzle to form a hollow jet of molten solder. (4) Direct gas to the transverse nozzle to assist in detaching and forming the hollow spheres. (5) Quickly cool and solidify the hollow spheres in flight by water mist. (6) Collect the hollow spheres.

\subsection{Experimental materials}

Table 1 shows some properties of eutectic tin-lead solder, water and argon. In Table 1, argon viscosity and density at $0.2 \mathrm{MPa}$ are from Stewart and Jacobsen ${ }^{(6)}$ and Younglove and Hanley ${ }^{(7)}$, respectively. Water properties are from Lide ${ }^{(8)}$. Density, surface tension and viscosity of solder at $227{ }^{\circ} \mathrm{C}$ are approximate values from Stankus and Khairulin ${ }^{(9)}$, Lee and Lee ${ }^{(10)}$ and Plevachuk et al. ${ }^{(11)}$, respectively. In comparison with pure water at room temperature, the molten eutectic tin-lead solder at 183 to $327{ }^{\circ} \mathrm{C}$ has a higher viscosity and higher surface tension. The high viscosity and surface tension of molten solder stabilize the formation of the hollow spheres.

The formation and breakup of hollow jet is affected by many parameters such as interfacial tensions, viscosities, densities, flow rates and so on. Therefore, constructing all non-dimensional parameters for the process would be extremely laborious and it is out of

Table 1. Properties of working materials

\begin{tabular}{cccccc}
\hline \multirow{2}{*}{ Property } & \multicolumn{2}{c}{ Argon gas } & Water & Sn63Pb37 \\
\cline { 2 - 3 } & At $27^{0} \mathrm{C}$ & At $227^{\circ} \mathrm{C}$ & & \\
\hline Melting temperature $\left({ }^{\circ} \mathrm{C}\right)$ & \multicolumn{2}{c}{-189} & 0 & 183 \\
Density $\left(\mathrm{kg} / \mathrm{m}^{3}\right)$ & 3.21 & 1.92 & 998 & 8076 \\
Viscosity $(\mathrm{mPa} . \mathrm{s})$ & 0.023 & 0.034 & 1.0 & 2.3 \\
Surface tension $(\mathrm{mN} / \mathrm{m})$ & & & 72.75 & 306 \\
\hline
\end{tabular}


our present study. Instead, we have considered a few non-dimensional parameters with the goal of achieving a preliminary understanding of the process. The parameters are as follows:

$$
\begin{array}{ll}
\text { Reynolds numbers: } & \operatorname{Re}_{\mathrm{o}}=\frac{\rho_{\mathrm{o}} U_{\mathrm{o}} \delta}{\mu_{\mathrm{o}}}, \mathrm{Re}_{\mathrm{i}}=\frac{\rho_{\mathrm{i}} U_{\mathrm{i}} d_{\mathrm{i}}}{\mu_{\mathrm{i}}} \\
\text { Capillary number: } & \mathrm{Ca}_{\mathrm{o}}=\frac{\mu_{\mathrm{o}} U_{\mathrm{o}}}{\sigma} \\
\text { Weber number: } & \mathrm{We}_{\mathrm{i}}=\frac{\rho_{\mathrm{i}} d_{\mathrm{i}} U_{\mathrm{i}}^{2}}{\sigma} \\
& q_{\mathrm{i}} / q_{\mathrm{o}}
\end{array}
$$

where the subscripts o and i respectively stand for water or molten solder and argon gas. We respectively denote the viscosity, interfacial tension, density, flow rate, velocity, inner diameter of the inner nozzle and annular distance by $\mu, \sigma, \rho, q, U, d$ and $\delta$. Re represents the ratio of inertial to viscous forces, $\mathrm{Ca}$ indicates the ratio between the viscous and capillary forces, and the ratio between inertial and capillary forces is expressed by We. The choice of $\mathrm{Ca}_{\mathrm{o}}$ and $\mathrm{We}_{\mathrm{i}}$ follows Ref. (12). All values of these parameters were calculated from approximate data assumed as follows: (1) We neglected the effect of tracers on the viscosity, density and surface tension of water. (2) The seeded water-argon and molten solder-argon interfacial tensions were surface tensions of pure water and of molten solder as given in Table 1.

\begin{tabular}{|c|c|c|c|c|c|c|c|c|c|}
\hline \multirow[b]{2}{*}{ Case } & \multirow[b]{2}{*}{$\mathrm{q}_{\mathrm{i}}$} & \multirow[b]{2}{*}{$\mathrm{q}_{\mathrm{o}}$} & \multirow[b]{2}{*}{$\mathrm{q}_{\mathrm{i}} / \mathrm{q}_{\mathrm{o}}$} & \multirow[b]{2}{*}{$\operatorname{Re}_{i}$} & \multirow[b]{2}{*}{$\operatorname{Re}_{\mathrm{o}}$} & \multirow[b]{2}{*}{$\mathrm{We}_{\mathrm{i}}$} & \multicolumn{3}{|c|}{ Transverse jet } \\
\hline & & & & & & & \multicolumn{3}{|c|}{$\left(\times 10^{-7} \mathrm{~m}^{3} / \mathrm{s}\right)$} \\
\hline $33-67^{a}$ & 33 & 67 & 0.5 & 198 & 326 & 0.295 & 0.03 & $N A^{b}$ & $S^{c}$ \\
\hline $0-42$ & 0 & 42 & 0 & 0 & 717 & 0 & 0.01 & NA & $F^{d}$ \\
\hline $100-68$ & 100 & 68 & 1.5 & 240 & 1175 & 0.377 & 0.017 & NA & $\mathrm{F}$ \\
\hline $53-33$ & 53 & 33 & 1.6 & 127 & 574 & 0.105 & 0.008 & NA & $\mathrm{F}$ \\
\hline $60-33$ & 60 & 33 & 1.8 & 145 & 574 & 0.138 & 0.008 & NA & $\mathrm{F}$ \\
\hline $68-33$ & 68 & 33 & 2.1 & 164 & 574 & 0.176 & 0.008 & NA & $\mathrm{FS}^{\mathrm{e}}$ \\
\hline $77-33$ & 77 & 33 & 2.3 & 182 & 574 & 0.218 & 0.008 & NA & FS \\
\hline $68-17$ & 68 & 17 & 4.0 & 164 & 287 & 0.176 & 0.004 & NA & FS \\
\hline $60-17$ & 60 & 17 & 3.5 & 145 & 287 & 0.138 & 0.004 & 283 & $\mathrm{~S}$ \\
\hline $153-22$ & 153 & 22 & 7.0 & 367 & 358 & 0.884 & 0.005 & 1000 & $\mathrm{~S}$ \\
\hline
\end{tabular}

\section{Results and Discussion}

Table 2 gives the summary of our experimental cases. The low Reynolds numbers strongly imply that coaxial jets were laminar. In addition, in all of our cases capillary forces can be inferred, from low Weber and Capillary numbers, to be dominant.

Table 2. Summary of experimental cases.

${ }^{a}$ indicates the apparatus performance test using water. ${ }^{b} \mathrm{NA},{ }^{\mathrm{c}} \mathrm{S},{ }^{\mathrm{d}} \mathrm{F}$ and ${ }^{\mathrm{e}} \mathrm{FS}$ respectively stand for not available, non-filamented spheres, fibers and filamented spheres. 


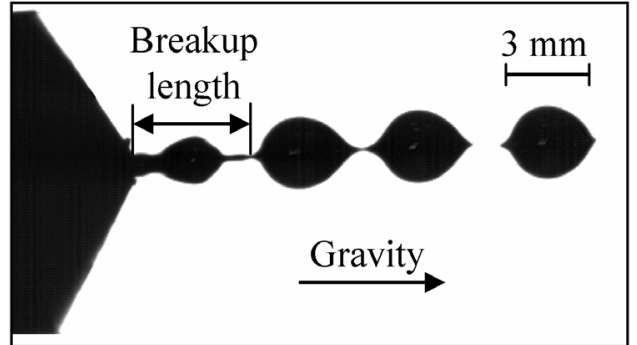

(a)

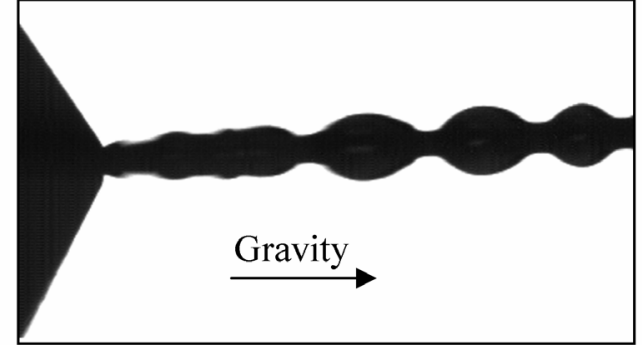

(b)

Fig. 5 (a) Formation of hollow eutectic tin-lead spheres without the transverse nozzle (case 68-17) and (b) hollow solder fiber with ripples on the surface (case 53-33).

We first tested the performance of the nozzle with seeded water as previously described with the camera operated at 6000 f.p.s (case 33-67). As seen from Fig. 4, hollow water spheres are produced, and in these conditions have a constant diameter of about $1.8 \mathrm{~mm}$, i.e., 2.25 times the inner diameter of the outer nozzle. The frequency of sphere formation was $567 \mathrm{~Hz}$. The figure shows that the apparatus and method work well with water.

Next, concerning production of hollow solder spheres, the annular space between the outer nozzle and inner nozzle of the coaxial nozzle is too small for molten solder to flow through it under the effect of gravity alone, but it can be forced out by applying pressure from an argon tank. If the heating temperatures of the crucible and nozzle are too high, the duration of sphere solidification will be longer, requiring a long falling distance. Also, reduction of viscosity and surface tension of solder due to the temperature increase adversely affects the stability of the formation of hollow solder spheres. On the other hand, a lower heating temperature that is still above the melting point of solder, leads to filamented spheres or, in the worst case, causes solder to choke the nozzle. We found that maintaining crucible and nozzle temperatures at about $50{ }^{\circ} \mathrm{C}$ above the melting point of solder was suitable.

The purpose of the cooling water sprayer is to rapidly cool and solidify the molten spheres. Thereby, the falling distance is reduced. The location of the cooling system is important; if it is too close to the coaxial nozzle, spheres will solidify before surface tension makes them spherical. However if the cooling system is too far down, some spheres will break up before being cooled and solidifying because of the wide difference in pressure between the inside and outside of the spheres. In our study, disposing the cooling system from 30 to $50 \mathrm{~cm}$ below the coaxial nozzle was found to work reasonably.

Figure 5 (a) shows the formation of hollow eutectic tin-lead spheres for case 68-17. The frequency of hollow solder sphere formation was about $157 \mathrm{~Hz}$. The camera was run at 2000 f.p.s. The average outer diameter of spheres was about $3 \mathrm{~mm}$, i.e, 3.75 times the inner diameter of the outer nozzle. The smaller values of $\mathrm{We}_{\mathrm{i}}$ and $\mathrm{Ca}_{0}$, as compared with those in the water case (case 33-67) imply that the breakup length of molten solder jet should be shorter. This is confirmed by a comparison of Figs. 5 (a) and 4, where the breakup length of the solder jet is about half that of the water jet. As seen in Fig. 5 (a), the spheres are not round, rather they have distinctive tails in front and behind them where neighboring hollow spheres connect to each other. On the other hand, hollow water spheres show a uniform size as shown in Fig. 4. The non-sphericity of solder spheres is probably the result of rapid cooling and partial freezing of filament of molten

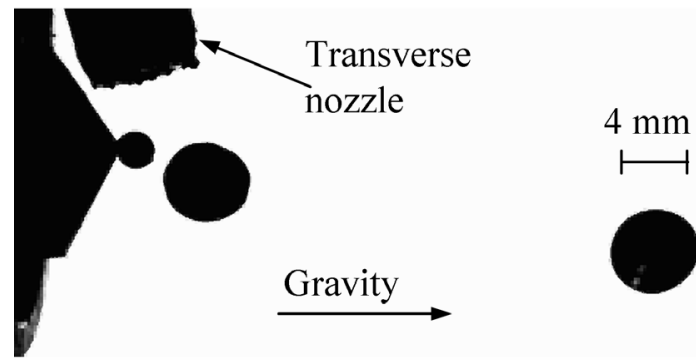

Fig. 6 The transverse nozzle effects on the formation and detachment of hollow solder spheres (case 60-17). 


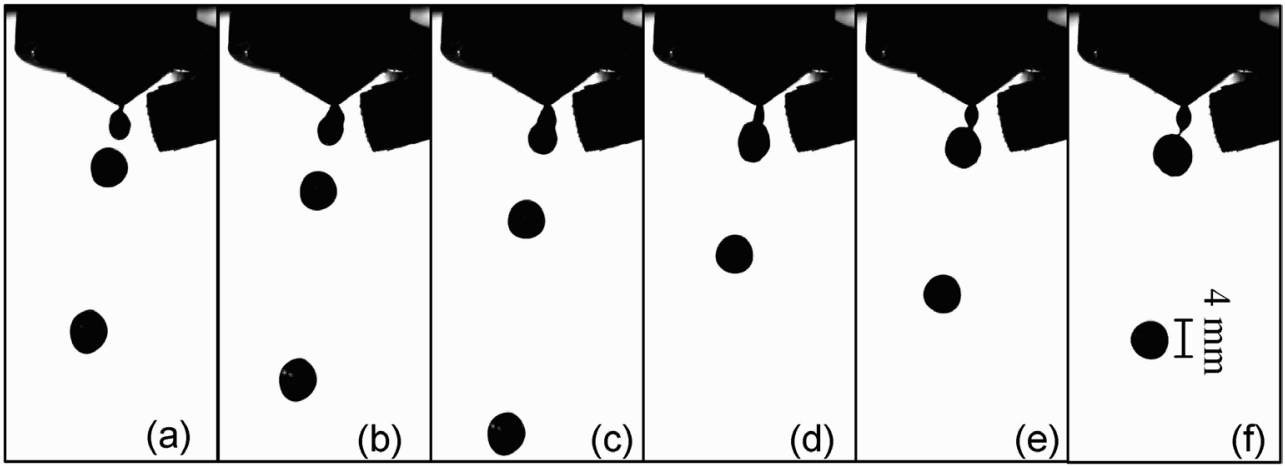

Fig. 7 The evolution of the solder jet until encapsulation. The time interval between images is $0.0075 \mathrm{~s}$ (case 153-22).

solder formed temporarily during the breakup process ${ }^{(13)}$ when the formation of spheres was conducted at room temperature. Therefore, the surface tension force acted too slowly to make hollow drops spherical unlike those found in the case of water. Another factor that assisted this undesired formation was the oxidation at the sphere surface. Oxidation reduces the surface tension of molten metal and increases its viscosity significantly ${ }^{(14)}$ which reduces the frequency of sphere formation and increased the outer diameter of hollow spheres. Even worse, in certain cases of our experiments, an oxide layer forming on the molten solder jet surface caused the jet to form hollow fibers with ripples on their surface as shown in Fig. 5 (b) (case 53-33). Therefore, it is highly desirable to maintain a sufficiently low content of oxygen in the surrounding gas where hollow metal spheres are formed.

Figure 6 shows the formation of hollow solder spheres when there was assistance of the transverse nozzle that directed an inert gas past the hollow molten solder jet in order to detach and form hollow spheres. The transverse nozzle also helped to prevent the coalescence of hollow spheres during falling ${ }^{(4)}$, and suppressed oxidation by reducing the oxygen content in the region of sphere breakup. For Fig. 6, the transverse nozzle directed argon gas at $283 \times 10^{-7} \mathrm{~m}^{3} / \mathrm{s}$ (case 60-17) and the camera was run at 2000 f.p.s. As seen from Fig. 6, spheres were formed without filaments.

In Fig. 7, the breakup process is observed in closer detail for case 153-22 with the camera run at 2000 f.p.s, with images extracted here at intervals of $0.0075 \mathrm{~s}$. The flow rate of transverse jet was $1000 \times 10^{-7} \mathrm{~m}^{3} / \mathrm{s}$. The transverse jet caused the breakup to repeat nearly periodically. The phase difference between neighboring images is about $72^{0}$. At the beginning of the sequence, as seen from Fig. 7 (a), the molten solder jet sealing the gas appears as a nearly spherical bag connected to the outer nozzle, but blown leftward because of the argon flow coming from the transverse nozzle. As time advances, the jet elongates and grows in volume. The surface tension force combined with the continued movement of the transverse flow causes the jet to break up (Fig. 7 (f)). Some hollow solder spheres with

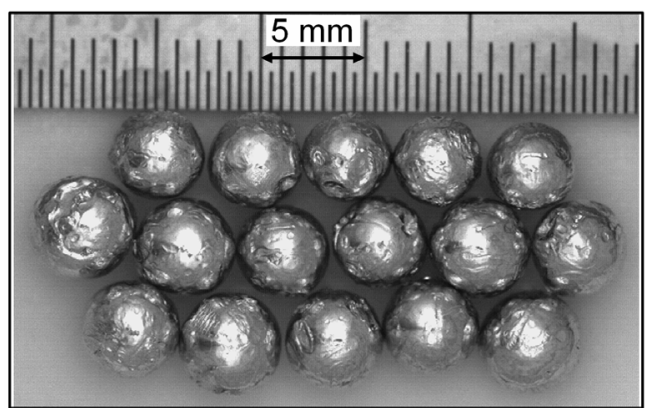

(a)

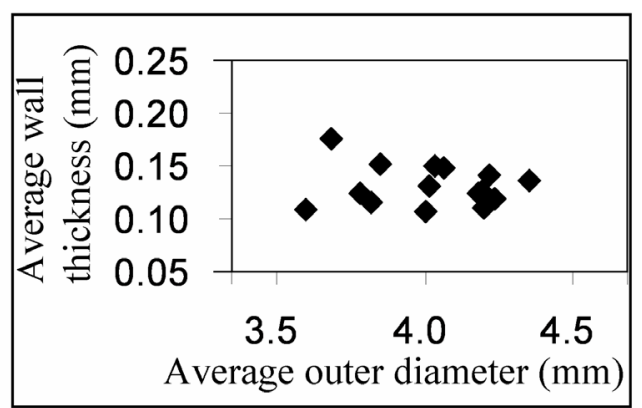

(b)

Fig. 8 (a) Hollow eutectic tin-lead solder spheres (case 153-22) and (b) average wall thickness of some hollow solder spheres for case 153-22. 
relatively smooth surfaces produced in this case are depicted in Fig. 8 (a). However, these spheres were not uniform in size; outer diameters varied in the range of 3.5 to $4.5 \mathrm{~mm}$ with the average wall thickness in the range of 0.1 to $0.2 \mathrm{~mm}$, as shown in Fig. 8 (b). In Fig. 8 (b), the average wall thickness was $R_{\mathrm{o}}-R_{\mathrm{i}}$ in which $R_{\mathrm{o}}$ is the outer radius and the inner radius $R_{\mathrm{i}}$ of the hollow sphere is estimated by

$$
R_{\mathrm{i}}=\sqrt[3]{R_{\mathrm{o}}^{3}-\frac{3 m_{\mathrm{s}}}{4 \pi \rho_{\mathrm{s}}}}
$$

where $\rho_{\mathrm{s}}$ is the solder density at room temperature ${ }^{(14)}, \rho_{\mathrm{s}}=8403 \mathrm{~kg} \cdot \mathrm{m}^{-3}$, and $m_{\mathrm{s}}$ is the measured weight of sphere (It was confirmed that the weight of enclosed argon was negligible). In addition to the non-uniformity in size, some spheres were not completely hermetic unlike the results achieved in co-flowing surrounding gas ${ }^{(5)}$ and not spherical. This is probably due to (1) the imperfection of water mist, i.e., it was not fine enough; (2) the impact of spheres on water surface in the collection container resulting in deformation of the spheres (because eutectic tin-lead solder is a soft metal and the wall thickness of the spheres is thin); and (3) sphere solidification before the spheres reached a spherical shape. Some spheres had cracks at the thinnest portions. We speculate that the cracks occurred some time after solidification, because of wide difference between the pressure within the spheres and the ambient pressure. Additionally, these cracks could be caused by growth grain during solidification.

In Fig. 9, micrographs of cross-sectioned halves of different hollow solder spheres are shown together with an image of solidified filamented spheres (Fig. 9 (d)). Figure 9 (a) shows half of a sphere that was formed from the case illustrated in Fig. 6 (case 60-17). This sphere has an average outer diameter of $4.3 \mathrm{~mm}$. Figures 9 (b) and (c) are two halves of spheres produced at the molten solder flow rate of $22 \times 10^{-8} \mathrm{~m}^{3} / \mathrm{s}$ and the argon flow rate of $153 \times 10^{-8} \mathrm{~m}^{3} / \mathrm{s}$ as shown in Fig. 7 (case 153-22). The average outer diameters are $4.0 \mathrm{~mm}$ (Fig. 9 (b)) and $3.5 \mathrm{~mm}$ (Fig. 9 (c)). These figures show that in addition to deformation and non-sphericity as mentioned above, these spheres are not concentric. The tendency for the gas within the hollow sphere to rise during falling caused the non-concentricity ${ }^{(15)}$.

However, for better performance of the production of hollow metal spheres, some matters that have not been done in our present study should be considered, as follows: (1) To prevent metallic hollow spheres from oxidizing during falling, the oxygen content of the surrounding gas has to be very low. (2) To quickly cool the hollow spheres, instead of using fine water mist, cooling gas of such materials as nitrogen, argon or helium at low temperature can be used. (3) To reduce the non-concentricity of hollow spheres, the formation of hollow spheres should be conducted in reduced gravity environment (13) combined with vibrations ${ }^{(15)}$.

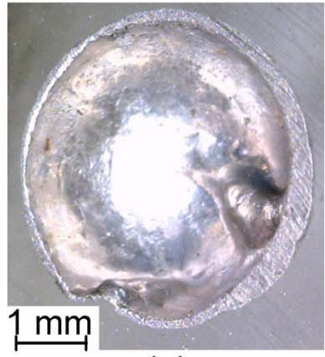

(a)

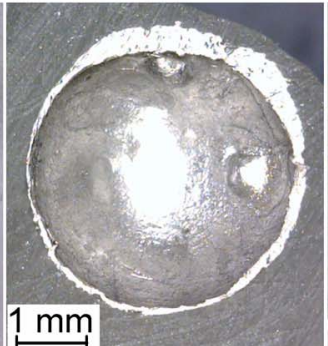

(b)

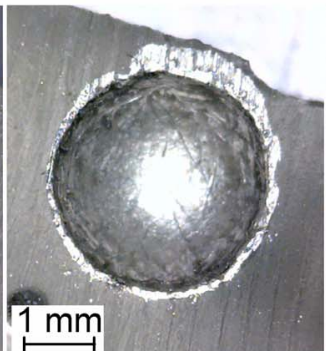

(c)

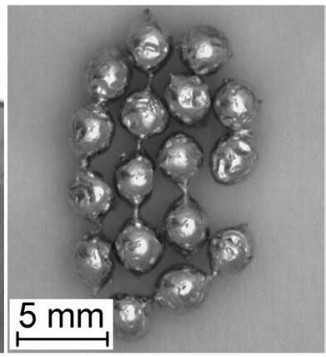

(d)

Fig. 9 (a), (b), (c) Microscope images of three halves of three hollow solder spheres and (d) solidified filamented spheres of solder. 


\section{Conclusions}

Non-filamented, hollow eutectic tin-lead solder spheres with relatively smooth surfaces, have been successfully produced. The spheres were formed by using a coaxial nozzle and the assistance of a transverse nozzle placed below the coaxial nozzle. Outer diameter of the spheres varied in the range of 3.5 to $4.5 \mathrm{~mm}$ with wall thickness in the range of 0.1 to 0.2 $\mathrm{mm}$.

\section{Acknowledgement}

This work was partially supported by the Japanese Government Ministry of Education, Culture, Sports, Science and Technology (MEXT). The authors would like to thank Mr. Hajime Yamaue for expert advice and machining, Dr. Yasuhiro Abe, Mr. Thien D. Nguyen and Ms. Anggraini Lydia for helpful discussions.

\section{References}

(1) Hollomet GmbH, available from <http://www.hollomet.com/cms>, (accessed 2010-07-27).

(2) Felton, R., Hollow Metal Spheres Put Fraunhofer on a Roll, Metal Powder Report, Vol.64, No.10(2009), pp.8.

(3) Waag, U., Schneider, L., Lothman, P. and Stephani, G., Metallic Hollow Spheres - Materials for the Future, Metal Powder Report, Vol.55, No.1(2000), pp.29-33.

(4) Torobin, L. B., "Metal Microspheres, Filamented Hollow Metal Microspheres and Articles Produced therefrom", U.S. Patent 4582534(1986).

(5) Nadler, J. H., Sanders, T. H. and Cochran, J. K., Aluminum Hollow Sphere Processing, Material Science Forum, Vol.331-337(2000), pp.495-499.

(6) Stewart, R. B. and Jacobsen, R. T., Thermodynamic Properties of Argon From the Triple Point to 1200 K with Pressures to $1000 \mathrm{MPa}$, Journal of Physical and Chemical Reference Data, Vol.18, No.2(1989), pp.639-798.

(7) Younglove, B. A. and Hanley, H. J. M., The Viscosity and Thermal Conductivity Coefficients of Gaseous and Liquid Argon, Journal of Physical and Chemical Reference Data, Vol.15, No.4(1986), pp.1323-1337.

(8) Lide, D. R. ed., CRC Handbook of Chemistry and Physics, 89 ${ }^{\text {th }}$ edition (2008) (CRC Press), pp.6_2.

(9) Stankus, S. V. and Khairulin, R. A., The Density of Alloys of Tin-Lead System in the Solid and Liquid States, High Temperature, Vol.44, No.3(2006), pp.389-395.

(10) Lee, J. H. and Lee, D. N., Use of Thermodynamic Data to Calculate Surface Tension and Viscosity of Sn-based Soldering Alloy Systems, Journal of Electronic Materials, Vol.30, No.9(2001), pp.1112-1119.

(11) Plevachuk, Yu., Sklyarchuk, V., Yakymovych, A., Willers, B. and Eckert, S., Electronic Properties and Viscosity of Liquid Pb-Sn Alloys, Journal of Alloys and Compounds, Vol.394, No.1-2(2005), pp.63-68.

(12) Utada, A. S., Fernandez-Nieves, A., Stone, H. A. and Weitz, D. A., Dripping to Jetting Transitions in Co-flowing Fluid Streams, Physical Review Letters, Vol.99, No.9(2007), pp.094502.1-094502.4.

(13) Kendall, J. M., Lee, M. C. and Wang, T. G., Metal Shell Technology based upon Hollow Jet Instability, Journal of Vacuum Science and Technology, Vol.20, No.4(1982), pp.1091-1093.

(14) Yim, P., The Role of Surface Oxidation in the Break-up Laminar Liquid Metal Jets, Ph.D Thesis (1996), Dept. of Mechanical Engineering, Cambridge, Massachusetts Institute of Technology.

(15) Frosh, R. A., Wang, T. G. and Elleman, D. D., "Method and Apparatus for Producing Concentric Hollow Spheres", U.S. Patent 4279632(1981). 